\title{
Performance Evaluation of Four Activated Partial Thromboplastin Time Reagents
}

\author{
Peppi Z.Yuzaqi, Eli Halimah, Tatat Novianti
}

Department of Pharmacology and Clinical Pharmacy, Faculty of Pharmacy, Universitas Padjadjaran, Jatinangor, West Java, Indonesia.

\begin{abstract}
Activated Partial Thromboplastin Time (APTT) is a hematological examination to identify hemostatic abnormalities. This study aimed to compare the performance evaluation of four APTT reagents, i.e., CK Prest, Pathromtin SL, Actin SL, and Cephascreen. The methods used were photo optical, percent detection, and viscosity-based detection system (VDS). The analysis was performed on blood specimen of 43 subjects. The results indicated that the accuracy and precision in normal plasma control using C. K. Prest reagent in Coag-A-Mate ${ }^{\circledR}$ MTX II were d\% -0.605 and CV\% 2.252\%, Pathromtin SL reagent in CA $560^{\circledR}\left(\right.$ Sysmex $\left.^{\circledR}\right)$ were $\mathrm{d} \% 6.9345$ and CV\%1.687, Actin FSL reagent in CA 560 ${ }^{\circledR}\left(\right.$ Sysmex $\left.^{\circledR}\right)$ were $\mathrm{d} \%-1.51$ and $\mathrm{CV} \%$ 1.74, and Cephascreeen reagent in STA Compact ${ }^{\circledR}$ were $\mathrm{d} \% 10.81$ and $\mathrm{CV} \% 1.60$. The accuracy and precision in pathological plasma control using Pathromtin SL reagent in CA $560^{\circledR}\left(\right.$ Sysmex $\left.^{\circledR}\right)$ were $\mathrm{d} \%-1,11$ and CV\% 8.82, Cephascreen reagent in STA Compact ${ }^{\circledR}$ were $\mathrm{d} \% 4.64$ and $\mathrm{CV} \%$ 2.72. The coefficient of correlation between C. K. Prest reagent and Pathromtin SL reagent was 0.880 with the regresion equation $y=2.31 x-33.70$. The coefficient of correlation between C. K. Prest reagent and Actin FSL reagent was 0.986 with the regretion equation $y=0.78 x+2.93$. The coefficient of correlation between C. K. Prest reagent and Cephascreen reagent was 0.987 with the regretion equation $y=1.70 x-3.97$. In conclusion, the best precision was obtained from Cephascreen reagents in STA compact ${ }^{\circledR}$ devices for both normal and pathologic control plasma, with eligible accuracy.
\end{abstract}

Keywords : Activated Partial Thromboplastin Time (APTT), Photo-optical, Viscositybased Detection System (VDS)

\section{Introduction}

Activated Partial Thromboplastin Time (APTT) is a hematological examination to identify hemostatic abnormalities of intrinsic and joint pathways through the control of clotting factors XII, preciprequin, quininogen, clotting factors XI, IX, VIII, X,
$\mathrm{V}$, prothrombin, and fibrinogen. The intrinsic pathway occurs sequentially and mutually activating from one factor to another. The initial chemical reaction will occur when bleeding (blood damage) which then will occur in contact with collagen, and leads to activation of factor XII. ${ }^{1}$

Corresponding author: Peppy Z. Yuzaqi. Department of Pharmacology and Clinical Pharmacy, Faculty of Pharmacy, Universitas Padjadjaran, Jatinangor, West Java, Indonesia. Email: kangzoelfian@gmail.com

Received: 26 May 2018. Revised: 4 Juni 2018. Published: 1 August 2018. 
Further, activated factor XII will affect the activation of factor XI, factor IX, factor VIII, and factor $\mathrm{X}$. The activated factor $\mathrm{X}$ will combine between the factor $\mathrm{V}$ and platelet or phospholipid tissue to form a complex called a prothrombin activator. A prothrombin activator within a few seconds initiates the splitting of the protrombin into thrombin, and further clotting processes may take place. ${ }^{1}$

Indication of abnormalities in the intrinsic blood clots is the presence of extending APTT. The normal range of extension is suggested between 20-39 seconds. The types of disorders that can cause the extending of APTT are disseminated intravascular coagulation (DIS), cirrhosis, factor XII deficiency, factor VIII deficiency (Hemophilia A), factor IX deficiency (Hemophilia B), and Lupus anticoagulant syndrome. ${ }^{2,3}$

The coagulation test of APTT can be evaluated using Coag-A-Mate ${ }^{\circledR}$ MTX II device using photo-optical principle method. The coagulation examination on this device begins by passing a light ray through the cuvette and is received by the photodetector then a filter located in front of the detector merely passing monochromatic light at a wavelength of $405 \mathrm{~nm}$ to the detector. Similarly, the analysis method using in the CA $560^{\circledR}\left(\right.$ Sysmex $\left.^{\circledR}\right)$ device is photo-optical based on light scattering and the coagulation end point determination. CA $560^{\circledR}\left(\right.$ Sysmex $\left.^{\circledR}\right)$ device uses Pathromtin SL (PSL) and Actin FSL (AFSL) reagents for APTT examination. The differences between the two reagents lies in their sensitivity to heparin, lupus anticoagulant, and factor deficiencies (factor VIII, IX, XI, XII). PSL reagent is very sensitive to heparin deficiency and factor deficiencies (VIII, IX, XI, and XII), while, AFSL is very sensitive to lupus anticoagulant syndrome. ${ }^{4}$
One of the mechanical method principle of coagulation device testing is viscosity-based detection system (VDS) which is used in STA Compact $^{\circledR}$ device. VDS is a technique based on the resistance of the steel balls drawn back and forth by an activator until it finds a condition where the viscosity increases and the amplitude decreases. ${ }^{4}$ Photo-optical principles can be used in patients who suffer from hyperlipemia, jaundice and hemolysis. The range of values obtained with this method is higher compared to devices that use mechanical methods which may be caused by the influence of hyperlipidemia, hyperbilirubinemia, or hemolysis. ${ }^{5}$

This study aimed to compare performance evaluation of four different reagents using different devices for APTT examination.

\section{Methods}

Sample collection

Samples were obtained from patients who performed routine examinations of APTT at Prodia Clinical Laboratory, Jakarta using the Coag-A-Mate ${ }^{\circledR}$ MTX II device. The samples were then analyzed in CA $560^{\circledR}$ $\left(\right.$ Sysmex $^{\circledR}$ ) device and STA Compact ${ }^{\circledR}$ device. Phatological samples were obtained from Dharmais Cancer Hospital, Jakarta.

\section{Data analysis}

The analysis involved the comparison of accuracy and precision in normal plasma control samples and pathological plasma control samples. Correlation and regression analysis were compared between C.K. Prest in Coag-A-Mate ${ }^{\circledR}$ MTX II devices and PSL reagents, C.K. Prest reagents in Coag-AMate $^{\circledR}$ MTX II and AFSL reagents in CA $560^{\circledR}\left(\right.$ Sysmex $\left.^{\circledR}\right)$ device, C.K. Prest reagents in Coag-A-Mate ${ }^{\circledR}$ MTX II devices and Cephascreen reagents in the STA Compact ${ }^{\mathbb{B}}$ device. 
Table 1. Accuracy and precision of reagents in normal and pathological plasma samples

\begin{tabular}{|c|c|c|c|}
\hline & & Normal Plasma & Pathological Plasma \\
\hline \multirow{2}{*}{$\begin{array}{c}\text { Coag-A-Mate }{ }^{\circledR} \text { MTX II / } \\
\text { C. K. Prest }\end{array}$} & Accuration $(\mathrm{d} \%)$ & $-0.61 \%$ & - \\
\hline & Precision $(\mathrm{CV} \%)$ & $2252 \%$ & - \\
\hline \multirow[t]{2}{*}{ Sysmex ${ }^{\circledR}$ PSL } & Accuration $(\mathrm{d} \%)$ & $6935 \%$ & $-1.11 \%$ \\
\hline & Precision $(\mathrm{CV} \%)$ & $1687 \%$ & $8.82 \%$ \\
\hline \multirow[t]{2}{*}{ Sysmex $®$ AFSL } & Accuration $(\mathrm{d} \%)$ & $-1.51 \%$ & - \\
\hline & Precision $(\mathrm{CV} \%)$ & $1.74 \%$ & - \\
\hline \multirow{2}{*}{$\begin{array}{c}\text { STA Compact } \AA / \text { Cephas- } \\
\text { creen }\end{array}$} & Accuration $(\mathrm{d} \%)$ & $10.81 \%$ & $4.64 \%$ \\
\hline & Precision $(\mathrm{CV} \%)$ & $1.60 \%$ & $2.72 \%$ \\
\hline
\end{tabular}

\section{Results and Discussion}

\section{APTT examination result}

The accuracy and precision of different reagents in normal and pathological plasma samples can be seen in the Table 1. Currently, the different methods were used for APTT examination, including photo-optical analysis and VSD methods. In order to know which method is the most optimal, many studies have been conducted on various aspects of examination, including accuracy and precision, ease of examination techniques, the stability of reagents, and costs.

The coefficient of correlation (R) between the Coag-A-Mate ${ }^{\circledR}$ MTX II device with C. K. Prest reagent and the CA $560^{\circledR}\left(\right.$ Sysmex $\left.^{\circledR}\right)$ device with PSL reagent was 0.88 with regression equation $y=2.31 x-33.70$. The $\mathrm{R}$ was 0.880 which meant that the correlation was weak.

The R between Coag-A-Mate ${ }^{\circledR}$ MTX II with K. Prest reagent and the CA $560^{\circledR}\left(\right.$ Sysmex $^{\circledR}$ ) with ASL reagent was 0.986 with regression equation $y=0.78 x+2.93$, respectively. Based on the above results, the $\mathrm{R}$ was 0.986 , which meant that the correlation was strong.

The $\mathrm{R}$ between Coag-A-Mate ${ }^{\circledR}$ MTX II device with reagent $\mathrm{C}$. K. Prest reagent and STA Compact ${ }^{\circledR}$ device with Cephascreen reagents was 0.990 with regression equation $y=1.70 x-3.97$, respectively. The calculation of $\mathrm{R}$ and $\mathrm{R}^{2}$ according to the regression equation for STA Compact ${ }^{\circledR}$ were 1.70 and 3.97 (Coag-A-Mate ${ }^{\circledR}$ MTX II). Based on the above results, the $\mathrm{R}$ was 0.987 , which meant that the correlation was strong.

The validity of the analytical procedure characterized by its precision and accuracy values. The accuracy and precision are determined by the repetition of measurements from the same sample for the study, which must be stable and identical to each other with regard to the parameters investigated. Precision is defined as the ability of a measurement to be consistently reproduced and to the number of significant digits to

Table 2. The correlation and regression value results

\begin{tabular}{lcc}
\hline \multicolumn{1}{c}{ Status } & Correlation (R) & Equation \\
\hline CAM MTX II and Sysmex PSL & 0.880 & $y=2.31 x-33.70$ \\
\hline CAM MTX II and Sysmex AFSL & 0.986 & $y=0.78 x+2.93$ \\
\hline CAM MTX II and STA Compact & 0.987 & $y=1.70 x-3.97$ \\
\hline
\end{tabular}




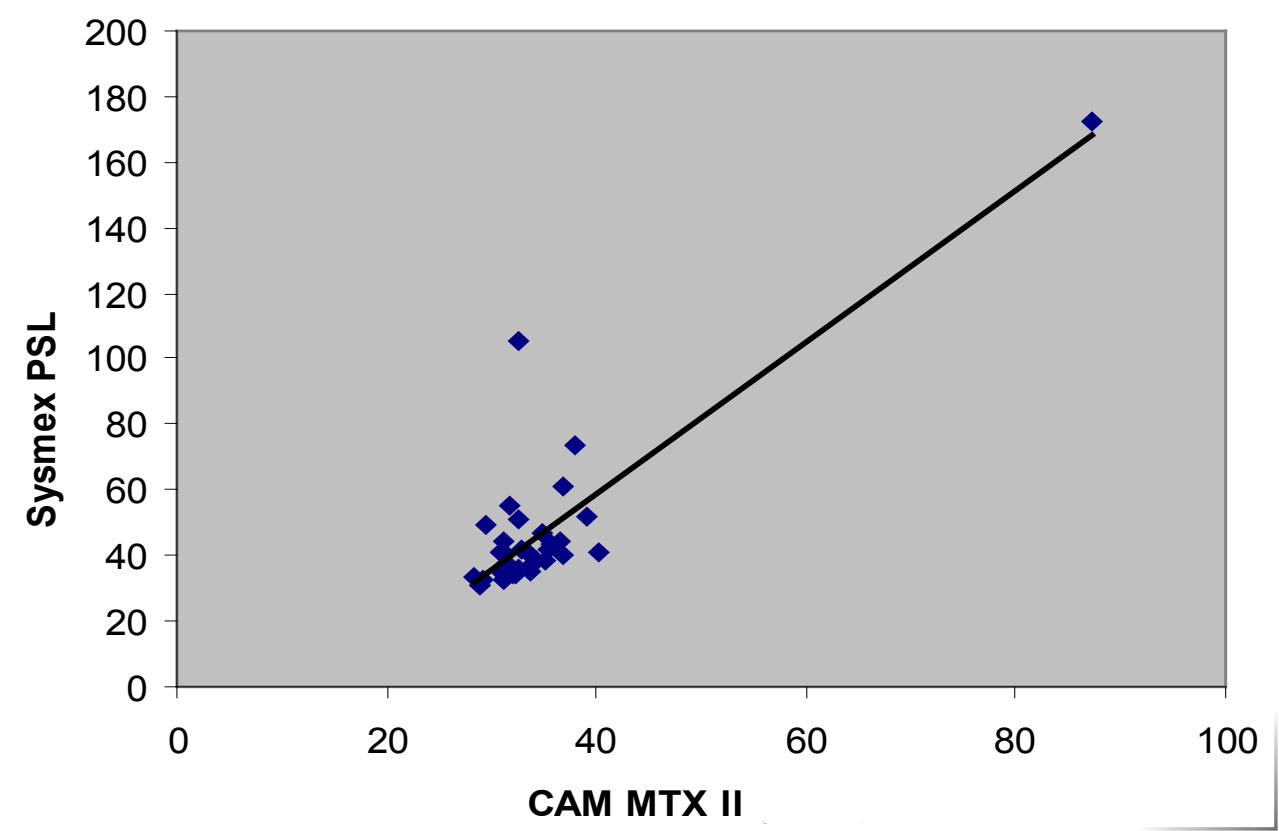

Figure 1. The extending of APTT correlation graph in Coag-A-Mate ${ }^{\circledR}$ MTX II with C. K. Prest reagent and $\mathrm{CA} 560^{\circledR}\left(\right.$ Sysmex $\left.^{\circledR}\right)$ with PSL reagent.

which value has been reliably measured. While accuracy refers to the ability of a measurement to match the actual value of the quantity being measured. Thus, the aim of this study is to obtain the precision and accuracy values of each analysis devices using normal and pathological plasma control. ${ }^{6}$

The precison value of normal control plasma in Coag-A-Mate ${ }^{\circledR}$ MTX II device with C. K. Prest reagents showed a good values with $2.252 \%$ of the coefficient variation $(\% \mathrm{CV})$ obtained. The accuracy of Coag-A-Mate ${ }^{\circledR}$ MTX II device with C. K. Prest ${ }^{\circledR}$ reagents was $-0.605 \%$. The accuracy has met the normal control values (26.4-37.6 seconds) listed in the C. K. Prest reagent insert kit.

The next device is CA 560® $\left(\right.$ Sysmex $\left.^{\circledR}\right)$ with PSL reagent. The precision value of the $\mathrm{CA}$ $560{ }^{\circledR}\left(\right.$ Sysmex $\left.^{\circledR}\right)$ device of the PSL reagent was $1.687 \%$ of $\% \mathrm{CV}$. The accuracy of this device was $6.935 \%$. The range of normal plasma control value from PSL was 29-40.2 seconds. For the CA $560 \AA\left(\right.$ Sysmex $\left.^{\circledR}\right)$ AFSL reagent device, the plasma precision control values showed good value. The value of $\%$ CV was $1.74 \%$. A good accuracy was $-1.51 \%$. The range of normal plasma control value was normally $24.5-32.8$ seconds.

The STA Compact ${ }^{\mathbb{B}}$ with Cephascreen reagent has a better value with $\% \mathrm{CV}$ of $1.60 \%$. The accuracy of STA Compact ${ }^{\mathbb{B}}$ has the highest value compared to the previous device, which was $10.81 \%$ and still in the range of plasma control values specified in the insert kit (2334.8 seconds).

The precision of the pathologic plasma control was also evaluated between all devices. The CA $560^{\circledR}\left(\right.$ Sysmex $\left.^{\circledR}\right)$ device with the PSL reagent was used and showed a slightly higher $\% \mathrm{CV}$, which is $8.82 \%$. The accuracy is good with deviation value of only $-1,11 \%$. In the STA Compact ${ }^{\circledR}$ device with Cephascreen reagent on the normal plasma control showed better value than the previous device, with a slightly lower CV\% of $2.72 \%$. The accuracy of this device is slightly higher with $4.64 \%$. In this case, reagent stability 


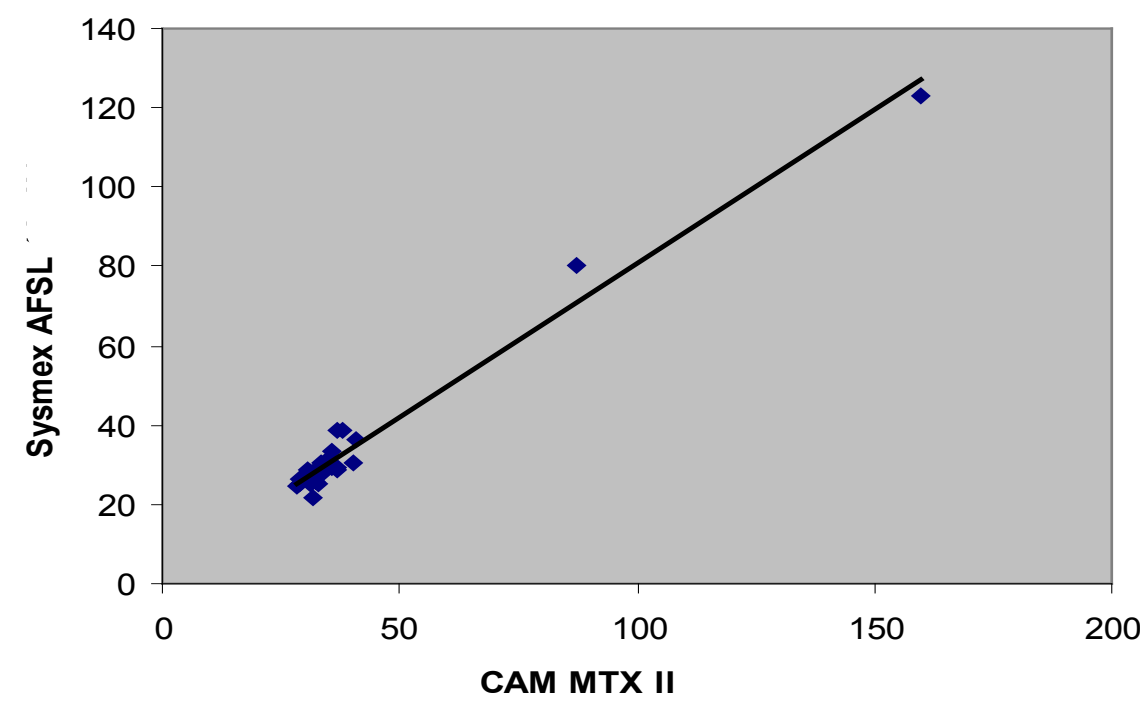

Figure 2. The extending of APTT correlation graphs in Coag-A-Mate ${ }^{\circledR}$ MTX II with C. K. Prest reagent and CA 560 ${ }^{\circledR}\left(\right.$ Sysmex $\left.^{\circledR}\right)$ with AFSL reagents.

is the important factor that will affect the precision and accuracy values related to the examination.

There are various things that will affect the stability of a reagent, such as dosage form and the reagent content. The comparison of APTT reagent is shown in Table 3. The differences in reagent form between liquid form and freeze-dried form can be observed.
The freeze-dried preparation will be less stable than the liquid preparation due to the unstable compound contained in the freezedried form if prepared in liquid preparation. The activator differences will also affect the reading of the results, such as the used of kaolin, silica, ellagic acid, and phospholipids. APTT reagents with silica are recommended for LA screening because of greater sensitivity. ${ }^{7}$

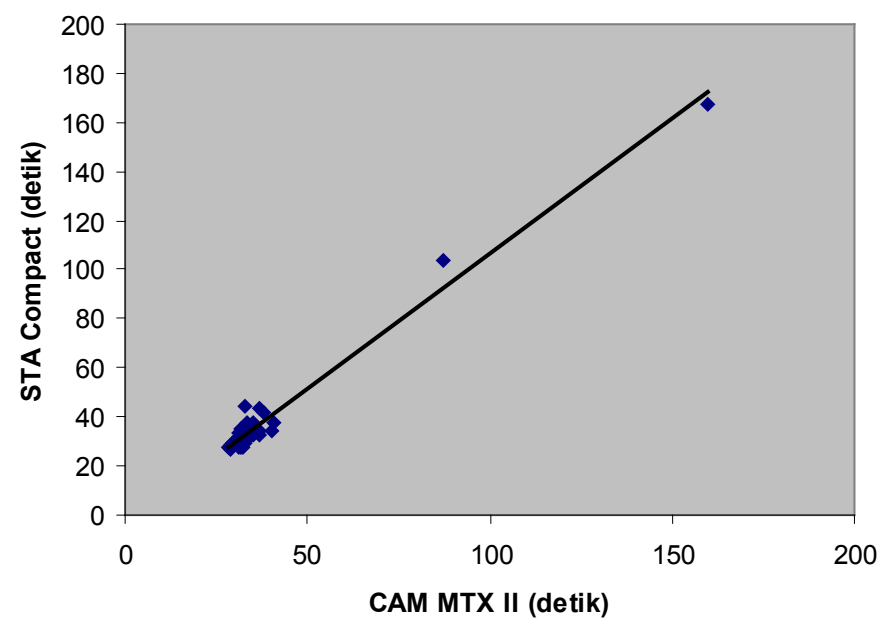

Figure 3. The extending of APTT correlation graphs in Coag-A-Mate ${ }^{\circledR}$ MTX II with C. K. Prest reagent and STA Compact ${ }^{\circledR}$ with Cephascreen reagent. 
The Coag-A-Mate ${ }^{\circledR}$ MTX II device has a photo-optical method and an automated system, starting from the piping, mixing, to interpretation of the result. Automated system plays an important part to obtain a better accuracy and precision values if compared to the manual system that allows a greater errors. $^{8}$

The CA 560® device (Sysmex ${ }^{\circledR}$ ) uses photooptical method based on light scattering and coagulation end-point detection. However, the automatic inspection technique need to be observed. In this CA $560 \AA$ (Sysmex ${ }^{\circledR}$ ) device, the sample did not show a big different change in the light scattering with the addition of reagents to the sample. The polymerization of fibrin monomer will be accelerated by the increase of coagulation reactions. The reaction mixture is then irradiated with ultra high light luminance light emission diode. The amount of light scattered at an angle of $90^{\circ}$ will be converted into an electrical signal to obtain a change in optical opacity of the reaction mixture. ${ }^{9}$

In addition to the light scattering method, the percent-detection method is also used in this device. The amount of light scattering after the addition of the reagent is considered to be $0 \%$ and the amount of light scattering in the coagulation reaction when the reaction has been completed is considered to be $100 \%$. During the period between $0 \%$ and $100 \%$, an end point is specified and the freezing time is then set for the percent end point. This percent detection value can be determined between $2 \%$ and $80 \%$. A $50 \%$ point is often used as a standard where the changes of light scattering per unit of time is significant and monofibrin polymerization reaction rate is high. ${ }^{9}$ The CA $560 \AA$ device (Sysmex $\AA$ ) is able to analyze more accurate coagulation based on the combination principle of light scattering and the measurement of the end point of the coagulation, particularly in samples with low fibrinogen, lipemic and haemolytic samples. ${ }^{9}$

Another device used in this APTT examination is STA Compact $\AA$. This device has a mechanical principle, which is based on VDS. This method works based on the technique of steel ball resistance drawn

Table 3. APTT reagent comparison

\begin{tabular}{|c|c|c|c|c|}
\hline & C. K. Prest & PSL & AFSL & Cephascreen \\
\hline Presentation & Freeze-dried & Liquid & Liquid & Liquid \\
\hline Activator & Kaolin & Micronized silica & Ellagic acid & Polyphenolic \\
\hline $\begin{array}{l}\text { Phospholipid } \\
\text { Combination }\end{array}$ & Rabbit brain & Vegetable & Rabbit brain & Rabbit brain \\
\hline $\begin{array}{l}\text { Stability after } \\
\text { Opening Capped }\end{array}$ & $\begin{array}{c}15^{\circ} \mathrm{C} \text { (open vial) } 2 \\
\text { days, 2-8OC } 1 \text { week }\end{array}$ & $\begin{array}{c}15^{\circ} \mathrm{C} \text { (open vial) } 2 \\
\text { days, } 2-8 \mathrm{OC} 2 \text { week }\end{array}$ & $\begin{array}{l}15^{\circ} \mathrm{C} \text { (open vial) } 2 \\
\text { days, } 2-8 \mathrm{OC} 1 \text { week }\end{array}$ & $\begin{array}{c}15^{\circ} \mathrm{C} \text { (open vial) } \\
1 \text { days, } 2-8 \mathrm{OC} 2 \\
\text { week }\end{array}$ \\
\hline \multirow[t]{2}{*}{ Package Size } & 1) $6 \times 2 \mathrm{ml}$ & 1) $1.10 \times 5 \mathrm{ml}$ & 1) $10 \times 2 \mathrm{ml}$ & 1) $12 \times 4 \mathrm{ml}$ \\
\hline & 2) $6 \times 5 \mathrm{ml}$ & 2) $20 \times 5 \mathrm{ml}$ & 2) $10 \times 10 \mathrm{ml}$ & 2) $12 \times 10 \mathrm{ml}$ \\
\hline FVIII Sensitivity & ++++ & ++++ & ++ & ++++ \\
\hline $\begin{array}{l}\text { FIX, XI, XII } \\
\text { Sensitivity }\end{array}$ & ++++ & ++++ & ++ & ++++ \\
\hline Heparin Sensitivity & +++ & ++++ & +++ & +++ \\
\hline
\end{tabular}


back and forth by an activator until it finds a condition where the plasma viscosity increases and the amplitude decreases due to the blood clotting process. ${ }^{10}$

Table 3 shows the precision and accuracy of each method. STA Compact ${ }^{\circledR}$ shows the best precision, while Sysmex ${ }^{\circledR}$ PSL has the best accuracy. The agreement of all tested devices and reagents is $58.14 \%$. The results of this agreement are closely related to the sensitivity of each reagent to heparin, the factors, lupus anticoagulant, and the method of the device used.

Most of the negative cases were encountered in the normal values of C. K. Prest reagent, AFSL reagents, and Cephascreen, while the PSL reagent showed abnormally high values. This results indicated that the patients were undergoing heparin therapy or factor VIII, IX, XI, and XII deficiencies. Another cases was also encountered in a normal values of C. K. Prest and AFSL reagent, whereas abnormal grades in PSL and Cephascreen reagent observed. This indicated that the patients were suspected to have factors VIII, IX, XI and XII deficiencies. The high abnormal values of Cephascreen reagent and normal values in CKP reagent, PSL, and AFSL were considered due to the factor VIII, IX, XI, XII deficiencies. The next case is the normal value of the reagent $\mathrm{C}$. K. Prest and abnormally high reagents in the PSL reagent, AFSL reagent and Cephascreen reagent. This suggests that the patient is most likely to have Lupus anticoagulant syndrome, then subsequent factor deficiency, and is currently undergoing heparin therapy or one of them.

Other different cases are normal values for AFSL reagent and high abnormal Cephascreen reagent in C.K. Prest reagent and PSL reagent. This suggests that the patient is suspected of having an anticoagulant lupus syndrome.
Normal values of C. K. Prest are low compared to AFSL, PSL and Cephascreen reagents. With these abnormally low values, the patient is suspected of having a factor deficiency or the patient is undergoing heparin therapy. Coupled PSL reagent is extremely sensitive for patients undergoing heparin therapy and factor VIII deficiency.

In this study, we also examined three samples from the Dharmais Cancer Hospital (with routine APTT elongated data) worked on at the Coag-A-Mate ${ }^{\circledR}$ MTX II device CA $560 \AA$ (Sysmex ${ }^{\circledR}$ ) and STA Compact ${ }^{\circledR}$ devices. The second sample provides APTT results that extend in three devices, even undetected (not clotting) in the CA 560® device (Sysmex ${ }^{\circledR}$ ) with PSL reagents, although the reading had been raised to 600 seconds (maximum time 600). This result can be explained due to the sensitivity of Pathromtin ${ }^{\circledR}$ SL reagents to heparin and factor VIII, IX, XI, XII therapies. Therefore, if the patients are treated with heparin and if the patients are having factors deficiency, the APTT will increase.

These three samples exhibited both extending and undetectable APTT results in CA 560® (Sysmex ${ }^{\circledR}$ ) devices with PSL reagents even though the maximum time had been extended to 600 . While, in the routine devices (CoagA-Mate ${ }^{\circledR}$ MTX II) they exhibited $>100$. Unfortunately, the reading time could not be extended due to the running out of sample. During APTT examination, samples were also examined for lipemic conditions (two samples with triglyceride concentration of 1200 and $400 \mathrm{mg} / \mathrm{dl}$, respectively) which were thought to affect optical measurement results in CA $560^{\circledR} \quad\left(\right.$ Sysmex $\left.^{\circledR}\right)$ devices. However, both samples gave nearly the same interpretation results within all of devices except on sample one giving slightly increased results (slightly above the reference value) in CA $560^{\circledR}$ device (Sysmex ${ }^{\circledR}$ ) using 
the PSL reagent. Thus, the effect of lipemic sample conditions on photo optical methods, both in Coag-A-Mate ${ }^{\circledR}$ MTX II and CA 560® devices was not proven in this study.

\section{Conclusion}

Cephascreen reagents in STA compact devices showed the best precision for both normal and pathologic control plasma, with eligible accuracy.

\section{Acknowledgement}

Not declared.

\section{Funding}

This research was funded by Prodia Clinical Laboratory.

\section{Conflict of Interest}

Not declared.

\section{References}

1. Ignjatovic V. Activated partial thromboplastin time. Methods in Molecular Biology. 2013;992:111-20.

2. Tagariello G, Radossi P, Salviato R. Clinical relevance of isolated prolongation of the activated partial thromboplastin time in a cohort of adults undergoing surgical procedures. Blood Transfusion. 2017;15(6):557-561.

3. Wheeler AP, Gailani D. The intrinsic pathway of coagulation as a target for antithrombotic therapy. Hematology/ Oncology Clinics of North America. 2016;30(5):1099-1114.

4. Kershaw G. Performance of activated partial thromboplastin time (APTT): Determining reagent sensitivity to factor deficiencies, heparin, and lupus anticoagulants. Methods in Molecular Biology. 2017;1646:75-83.

5. Lippi G, Plebani M, Favaloro EJ. Interference in coagulation testing: focus on spurious hemolysis, icterus and lipemia. Semin in Thrombosis and Hemostasis. 2013;39:258-266

6. Betz JM, Brown PN, Roman MC. Accuracy, precision, and reliability of chemical measurements in natural products research. Fitoterapia. 2011;82(1):44-52.

7. Kumano O, Ieko M, Naito S, Yoshida M, Takahashi N. APPT reagent with ellagic acid as activator shows adequate lupus anticoagulant sensitivity in comparison to silica-based reagent. Journal of Thrombosis and Haemostasis. 2012;10(11):2338-43.

8. Rathod NN, Nair SC, Mammen J, Singh S. Comparison study of routine coagulation screening tests (PT and APTT) by three automated coagulation analyzers. International Journal of Medical Science and Public Health. 2016;5(8):1563-1568.

9. Ratzinger F, Schmetterer KG, Haslacher H, Perkmann T, Belik S, Quehenberger P. Evaluation of the automated coagulation analyzer CS-5100 and its utility in high thriughput laboratories. Clinical Chemistry and Laboratory Medicine. 2014;52(8):1193-1202

10. Aggarwal S, Nayak DM, Manohar C. Discrepancy in optical \& mechanical method in coagulation tests in a turbid sample. Indian Journal of Hematology \& Blood Transfusion. 2014;30(Suppl 1):402-404 